\title{
Trigonocephaly: Long-term results after surgical correction of metopic suture synostosis
}

\author{
Piotr Wójcick ${ }^{A, D-F}$, Bernard Prudel ${ }^{B-D}$ \\ Department of Plastic Surgery, Wroclaw Medical University, Polanica-Zdrój, Poland \\ A - research concept and design; $B$ - collection and/or assembly of data; $C$ - data analysis and interpretation; \\ $D$ - writing the article; $E$ - critical revision of the article; $F$ - final approval of the article
}

Address for correspondence

Bernard Prudel

E-mail: bernardprudel@gmail.com

Funding sources

None declared

Conflict of interest

None declared

Received on June 26, 2017

Reviewed on July 14,2017

Accepted on May 5, 2018

Published online on January 30, 2019

Cite as

Wójcicki P, Prudel B. Trigonocephaly: Long-term results after surgical correction of metopic suture synostosis. Adv Clin Exp Med. 2019;28(5):625-635. doi:10.17219/acem/90763

DOI

10.17219/acem/90763

\section{Copyright}

Copyright by Author(s)

This is an article distributed under the terms of the

Creative Commons Attribution Non-Commercial License

(http://creativecommons.org/licenses/by-nc-nd/4.0/)

\begin{abstract}
Background. Premature closure and ossification of the metopic suture results in a triangular head shape called trigonocephaly and is characterized by a wedge-shaped forehead and frontotemporal narrowing. Untreated craniosynostosis may lead to increased intracranial pressure (ICP) and, thereby, impaired neurodevelopment. Over the last decades, its incidence has been increasing, currently making it the $2^{\text {nd }}$ most common type of isolated craniosynostosis. Treatment consist of cranioplasty, which should be performed before the age of 1 year.
\end{abstract}

Objectives. The aim of this study was to evaluate the long-term surgical outcomes in children operated on for trigonocephaly.

Material and methods. The authors reviewed 30 consecutive cases of metopic synostosis treated over a 14-year period in the Plastic Surgery Department in Polanica-Zdrój, Poland. The data was evaluated using the patients' clinical records, and preoperative and postoperative photographs. The patients showed up on a follow-up visit at a median age of 9 years and were examined by an ophthalmologist and a neurologist. The surgical outcomes were evaluated according to the Whitaker classification. In 23 patients, remodeling and the advancement of fronto-orbital skull segments was performed at a median age of 18 months and in 7 milder cases, simple suturectomy or burring of the metopic ridge was sufficient.

Results. According to the Whitaker classification, results were considered good to excellent (category I and II). Only 1 patient was included into category III. None of the examined cases were included into category IV, which would require a major craniofacial procedure, duplicating or exceeding the original operation. Neurological abnormalities were found in 12 cases and vision defects in 15 cases.

Conclusions. Trigonocephaly is currently the $2^{\text {nd }}$ most common type of isolated synostosis. Surgical treatment based on Tessier's and Marchac's modified methods provides good results in patients at the age of about 12 months and prevents the consequences of ICP increase. Primary neurological and behavioral disorders may occur, despite corrective surgery.

Key words: craniosynostosis, trigonocephaly, metopic synostosis 


\section{Background}

The term 'trigonocephaly' was first proposed by Welcker in 1862, who used it to describe a patient with a wedgeshaped scull combined with a cleft lip. Trigonocephaly is a congenital cranial deformation caused by premature fusion and ossification of the metopic suture. The metopic suture separates 2 frontal bones at birth and is the first skull suture to close physiologically, starting as early as at 3 months and generally being completely fused at the age of 8 months. In the case of trigonocephaly, premature synostosis takes place in the prenatal period. ${ }^{1}$ According to Virchow's theory, it results in the characteristic cranial malformation. ${ }^{2}$ Growth inhibition perpendicular to the synostosed suture induces frontotemporal narrowing and the shortening of anterior cranial fossa, and a compensative increase in the biparietal diameter and posterior cranial fossa. Triangular forehead deformity with protruding bony midline ridge may be accompanied by hypotelorism and ethmoid bone hypoplasia. In 55\% of cases, anterior fontanel is closed prematurely (Fig. 1-3). ${ }^{3}$

Trigonocephaly occurs either as an isolated malformation with or without another primary defect of morphogenesis and without any particular syndrome, or as a syndromic form. It is now estimated that $10-20 \%$ of patients with trigonocephaly are affected by syndromes such as Opitz C, Say-Meyer, Frydman, Baller-Gerold, Muenke, and Seathre-Chotzen, although most metopic synostosis are nonsyndromic. ${ }^{4,5}$ Trigonocephaly may be defined as a complex and heterogeneous condition supporting a strong genetic component accompanied by epigenetic and environmental factors affecting a child in prenatal period. There are 3 major theories defining this deformity formation. The first one assumes that cranium deformation results from genetic, metabolic or pharmacological agents. The second one considers intrauterine fetal head constraint caused by multiple gestation or uterine abnormalities. The third one considers the brain to be the main reason behind the onset of craniosynostosis. ${ }^{6}$

The most frequent associated malformations are limb, heart and genitourinary tract anomalies. In 38\% of cases, more than 1 extracranial malformation is diagnosed. In these patients, the IQ score is considerably lower than in patients with an isolated form. Moreover, these patients reveal intellectual disability, ADHD or autism spectrum disorders more often. ${ }^{7}$

Trigonocephaly prevalence has increased over the recent years. The latest researches reveal that this malformation is the second most frequent isolated craniosynostosis $(1: 5,000)$ and it may account for $23-28 \%$ of all isolated cases. The male to female ratio is reported to be about $3: 1$ and positive family history is found in $6.8 \%$ of patients. ${ }^{8-10}$

The goal of surgical treatment is the improvement of the forehead shape, hypotelorism correction and anterior cranial fossa extension. The procedure aims to obtain the normal development of the intensively growing brain.

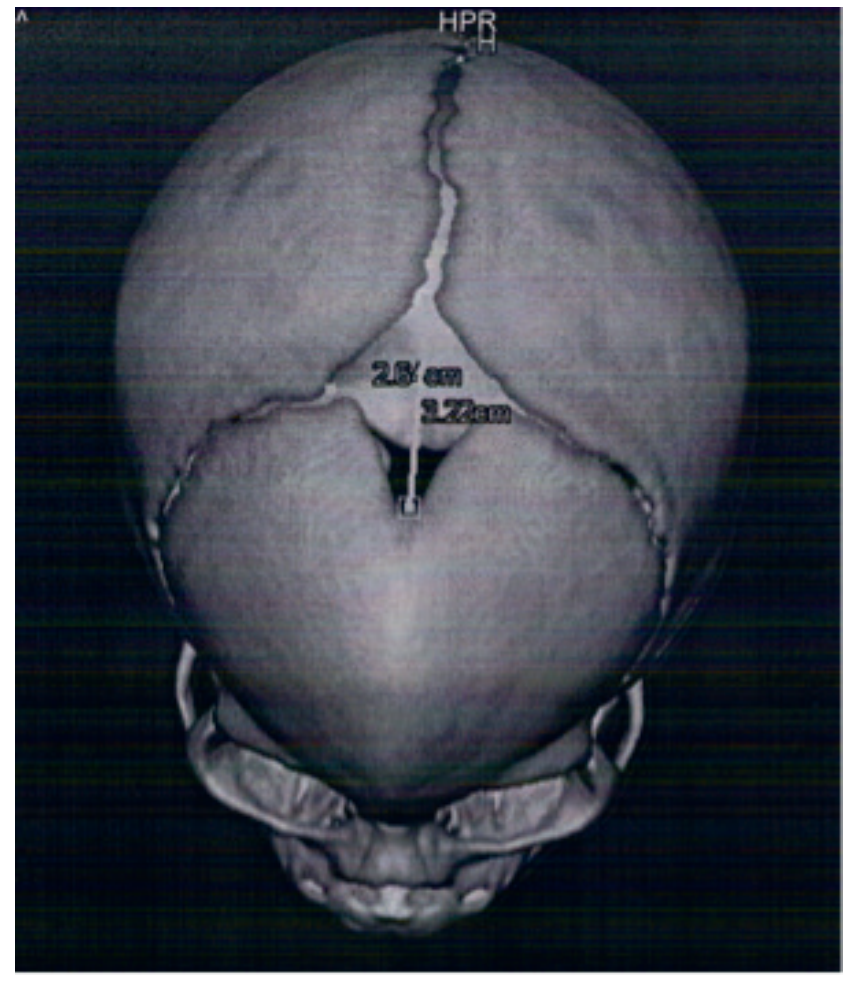

Fig. 1. Radiological features of trigonocephaly

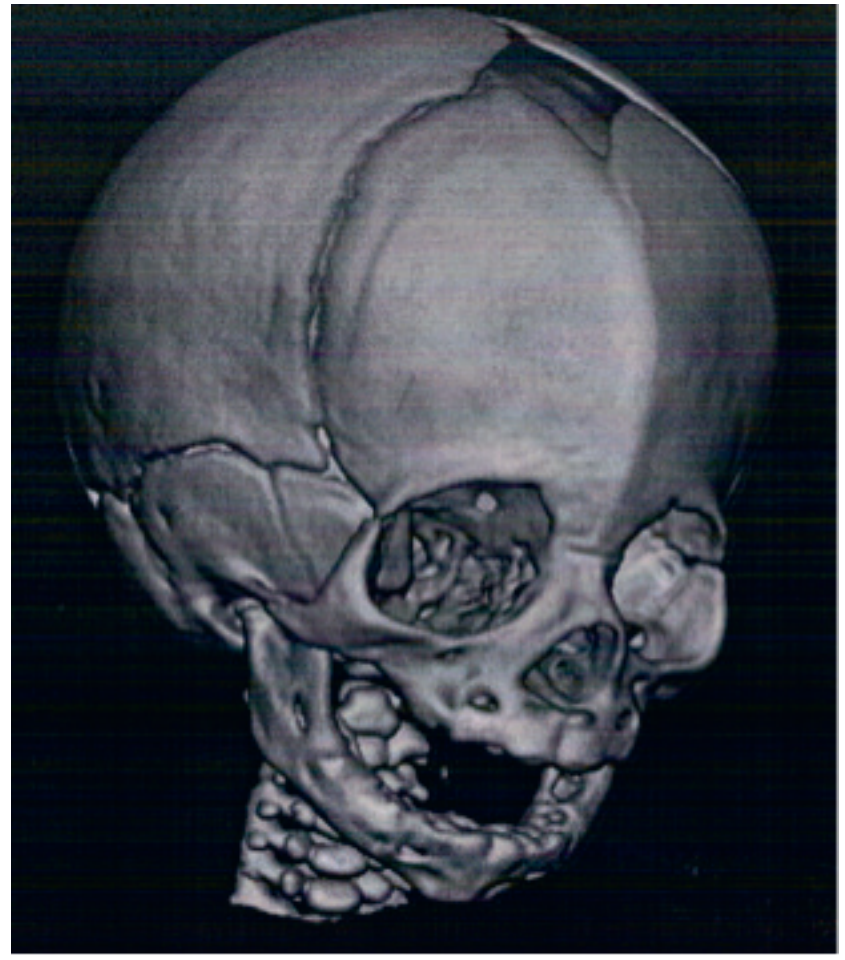

Fig. 2. Radiological features of trigonocephaly

Untreated isolated craniosynostoses may result in the increase of intracranial pressure (ICP) in $15-20 \%$ of cases. ${ }^{11}$ In trigonocephaly, visual defects like strabismus and astigmatism are common.

The majority of surgical techniques are based on forehead remodeling and anterior cranial fossa extension 


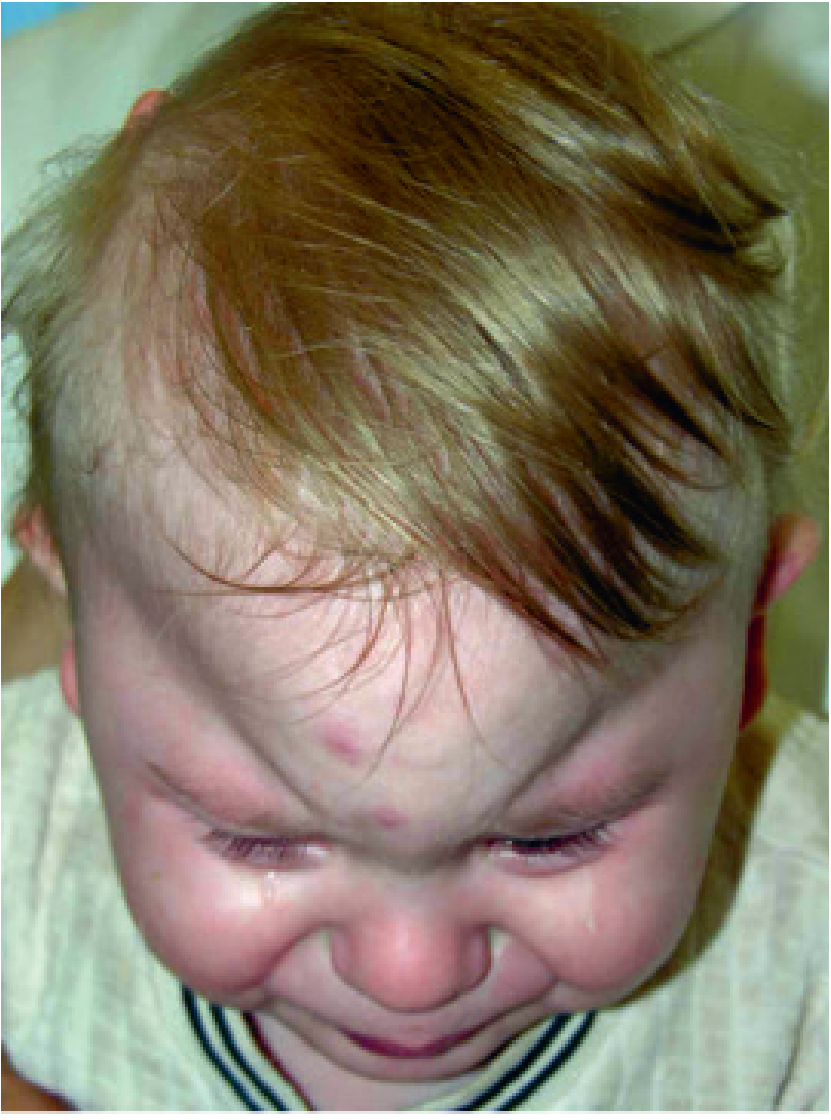

Fig. 3. Clinical features of trigonocephaly

by forehead and supraorbital bar advancement. ${ }^{12}$ Historically, procedures consisted only of the excision of synostosed cranial sutures-strip craniectomy. The breakthrough in the treatment of craniosynostosis came in 1971, when Paul Tessier proposed a horizontal advancement of the forehead along with the supraorbital area reaching the temporal fossae, the so-called fronto-orbital advancement (FOA). The advanced and remodeled forehead was fixed in a temporal fossa and nasal root area. ${ }^{13}$ In 1977, Marchac described cranioplasty based on bilateral cranial remodeling in infants with trigonocephaly, plagiocephaly and brachycephaly. The procedure, based on the concept of a "floating forehead", consists in advancing the supraorbital bar along with a remodeling the forehead, which was formed out of excised bones and sutured only on its lower edge. Such a floating forehead, which is not fixed to the cranial borders, leans against dura mater loosely and enables brain growth. ${ }^{14}$

The procedures presented above are regarded as basic treatment techniques of trigonocephaly and have undergone many modifications. ${ }^{15,16}$ The surgery should be performed at about $12^{\text {th }}$ month of life and surgical results are usually evaluated using the 4-degree Whitaker classification. ${ }^{17,18}$

The aim of this study was to evaluate the long-term surgical outcomes in children operated on fortrigonocephaly.

\section{Material and methods}

In years 2000-2014, in Plastic Surgery Department in Polanica-Zdrój (Wroclaw Medical University, Poland), 154 craniosynostotic patients were treated. This group of patients included 37 cases of trigonocephaly, of which 30 were analyzed in this study. Medical records were reviewed and the following data was retrospectively collected: sex, birth weight, gestation period and delivery course, age at operation, age at follow-up visit, other congenital deformities, time and type of surgical procedures, hospitalization length, treatment course, complications, and volume of transfused blood. All patients were consulted by an ophthalmologist and a neurologist, and the surgical treatment results were assessed with the Whitaker classification (Table 1).

Table 1. Whitaker classification of surgical results

\begin{tabular}{ll|} 
Category I & $\begin{array}{l}\text { No refinements or surgical revisions considered } \\
\text { advisable or necessary } \\
\text { Soft-tissue or lesser bone-contouring revisions advisable } \\
\text { apt to be performed on an outpatient basis or requiring } \\
\text { a maximum of 2-day hospitalization }\end{array}$ \\
\hline Major alternative osteotomies or bone grafting \\
procedure advisable, i.e., orbital repositions, onlay \\
bone grafts, being these procedures not so extensive \\
as the original operations \\
A major craniofacial procedure advisable, duplicating \\
Category IV exceeding the original operation
\end{tabular}

In addition, head measurements were taken, including the cranial index and head circumference. Moreover, blood for genetic test was collected and the results will be presented in a separate paper.

Surgical procedures were carried out using the Tessier's and Machac's modified method. It was based on the advancement and remodeling of the supraorbital band and forehead, leading to the enlargement of the anterior cranial fossa. Bicoronal skin incision was used to provide access. The skin was mobilized together with the galea and periosteal layer. Frontal bone and supraorbital band incision line was planned and craniotomy was carried out on the forehead and cranial vault border. After that, long supraorbital band reaching bilaterally to the temporal fossae was excised and was addressed by an wedge osteotomy on the posterior midline and lateral orbital wall in order to facilitate banding the bar in appropriate shape. Prepared osseous band was advanced by $1-1.5 \mathrm{~cm}$. In order to prevent recurrence of frontal narrowing and temporal hollowing, remodeled band was supported with bone grafts in median and lateral area. The frontal bones were cut in the midline and remodeled to fit in the new shape of the supraorbital band. After that, remodeled frontal bone was stitched to the osseous band with several vicryl sutures. According to the concept of "floating forehead", 
the posterior edge remained free. The skin flaps were closed tightly with mattress or simple sutures and drains were left for 2-3 days (Fig. 4-7). In mild metopic synostosis, simple synostectomy or milling the frontal midline prominence was sufficient.

\section{Results}

Among patients tested, there were 23 males (M) and $7 \mathrm{fe-}$ males (F); the M:F ratio was 3.31. Average birth weight was $3244 \mathrm{~g}, 16$ patients were delivered naturally and in 14 cases cesarean section was applied. Four patients were born prematurely. In 14 cases, gestation course was uneventful. In 3 mothers, gestational infection occurred, 8 mothers took medications mainly for hypothyroidism, 1 mother took valproic acid for epilepsy, and 1 was an alcoholic. One patient was delivered as a triplet after in vitro fertilization. Mothers of 11 patients admitted smoking cigarettes during pregnancy and in the period preceding fertilization (Table 2).

In none of the patients, familial history was detected. Before the procedure, genetic tests were made in 5 patients. In 2 patients, chromosomal aberrations were found - 9p syndrome (patients No. 24 and 28). In 1 patient, 1 and 22 chromosome polymorphism was diagnosed (patient No. 14) and in 1 patient, amniotic band syndrome was observed (patient No. 11). Only 5 patients were diagnosed geneticaly before surgery and they are listed above. In 8 patients, other extracranial malformations were found,

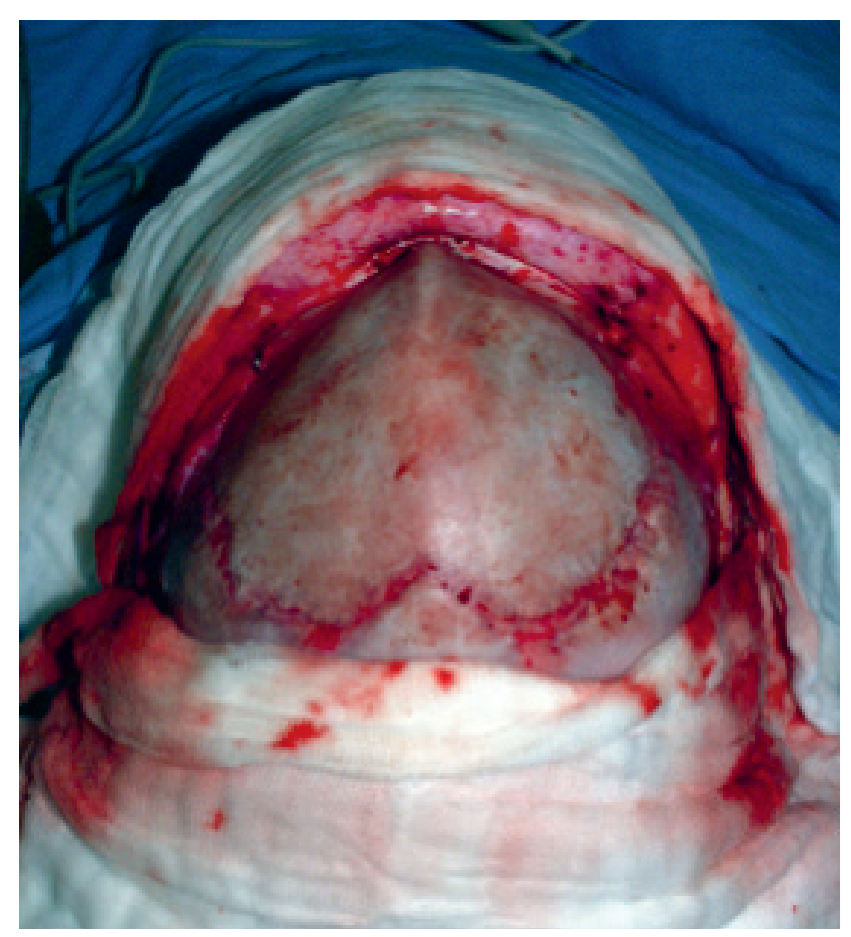

Fig. 4. Bicoronal skin incision used to provide access to the bone (skin is mobilized with the galea and periosteal layer)

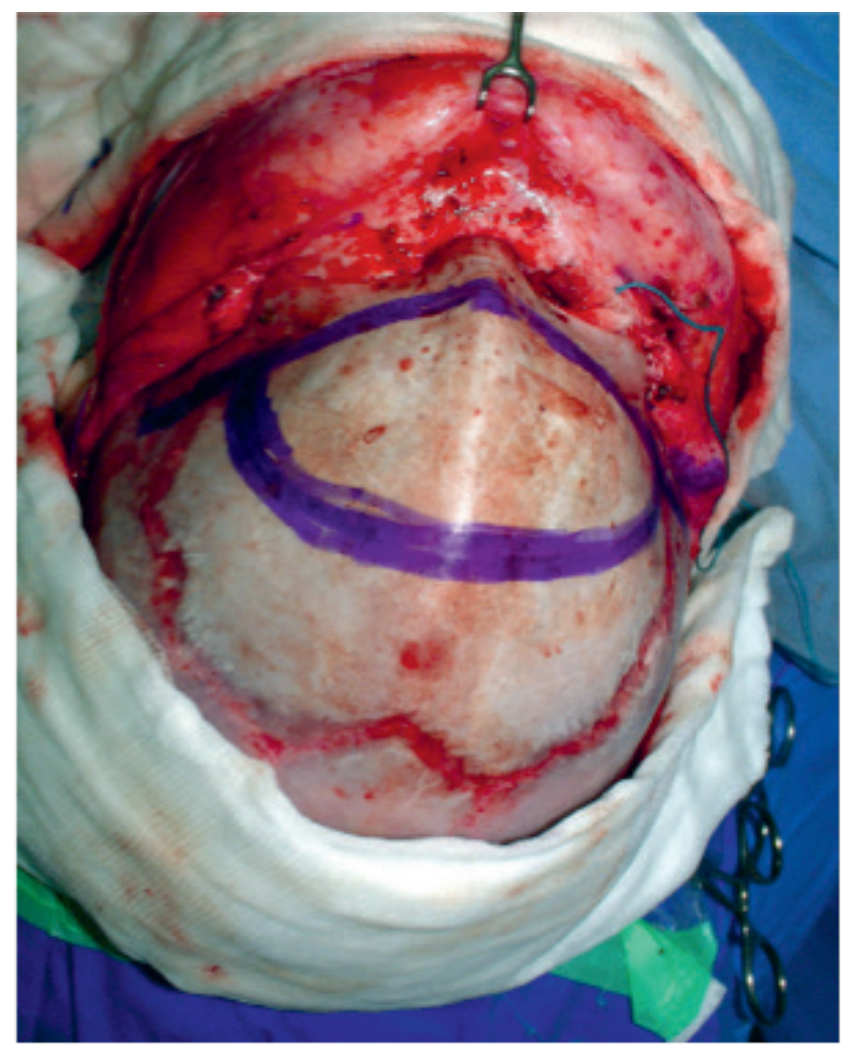

Fig. 5. Frontal bone and supraorbital band incision lines

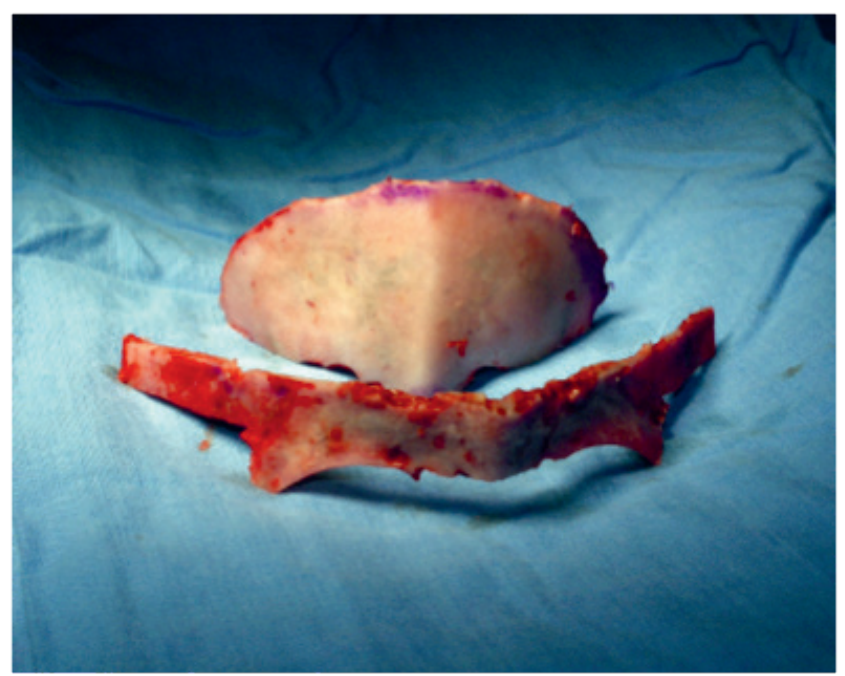

Fig. 6. Excised frontal bone and supraorbital band (before remodeling)

however, not as elements of any particular syndrome. More than 1 additional malformation was diagnosed in 4 patients. These abnormalities concerned mainly genitourinary tract. In 19 patients, no coexisting malformations were found (Table 3, 4).

In 23 cases, cranioplasty consisting of remodeling and advancement of fronto-orbital skull segments was performed and in 7 mild cases, simple synostectomy or burring of the frontal midline prominence was sufficient. Further analysis concerns the group of 23 cranioplasty patients. 


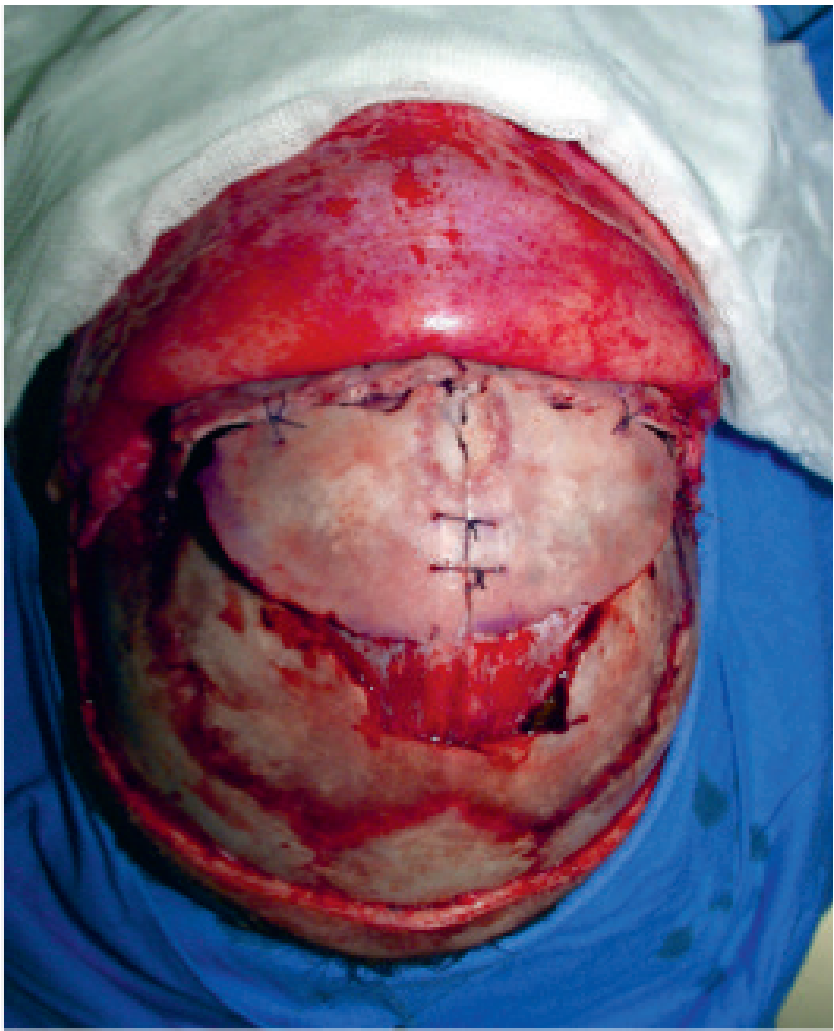

Fig. 7. Frontal bone and supraorbital band after remodeling and advancement
In our Department, patients are qualified for cranium remodeling and advancement at the age of 8-12 months. In the group of patients operated on $(n=23)$, average age at the surgery was 18 months. Ten patients were operated on before $12^{\text {th }}$ month of life (43\% of the operated patients). The youngest patient was operated on at the age of 4 months and the oldest syndromic child was operated on at the age of 84 months.

Average age of follow-up visit was 9 years. Twenty cranioplasties were performed by one of the authors of this publication. Surgical procedure average length was $3.7 \mathrm{~h}$. Blood was transfused in 21 patients (mean volume: $311 \mathrm{~mL}$, range: $180-750 \mathrm{~mL}$ ). Hospitalization mean time was 5.6 days (range: 3-10 days). No complications were observed in any of 23 operated cases. In 1 patient, in the surgery site, seroma formed but it was successfully evacuated. Preoperative assessment and qualification for the procedure was based on ophthalmological, neurological and imaging (X-ray and computed tomography) examinations. In 9 patients, additional intracranial abnormalities were found such as: frontal lobes hypoplasia, pericerebral fluid space or ventricular dilatation, arachnoid cyst, septum pellucidum cyst or cavity, corpus callosum agenesis, underdevelopment of ethmoid bone, or lateral nasal sinuses. In 12 patients, variety of neurological disorders were observed (psychomotor

Table 2. Medical history data on the course of pregnancy in examined cases

\begin{tabular}{|c|c|c|c|c|c|}
\hline Patient No. & Mother infection & Complications of pregnancy & Mother diseases & Other & $\begin{array}{l}\text { Smoking } \\
\text { cigarettes }\end{array}$ \\
\hline 2 & urinary tract & - & - & - & - \\
\hline 4 & boreliosis & - & - & - & - \\
\hline 5 & - & premature contractions & - & - & - \\
\hline 8 & - & premature contractions & - & - & yes \\
\hline 9 & - & - & hypothyroidism & - & - \\
\hline 10 & - & - & - & - & yes \\
\hline 11 & - & - & hypothyroidism & - & - \\
\hline 12 & - & premature placental abruption & - & - & yes \\
\hline 13 & - & - & hyperthyroidism, diabetes & - & - \\
\hline 14 & - & - & hypothyroidism & triple pregnancy by in vitro fertilization & - \\
\hline 15 & - & - & hypothyroidism & - & - \\
\hline 16 & - & - & - & - & yes \\
\hline 17 & - & - & - & - & yes \\
\hline 18 & - & - & hypertension & - & - \\
\hline 19 & - & - & - & - & yes \\
\hline 20 & - & - & alcoholism & - & yes \\
\hline 21 & - & - & hypertension & - & - \\
\hline 22 & - & premature contractions & - & - & yes \\
\hline 23 & - & - & - & - & yes \\
\hline 24 & intrauterine infection & - & - & - & - \\
\hline 26 & - & - & - & - & yes \\
\hline 27 & - & - & epilepsy & - & yes \\
\hline
\end{tabular}


Table 3. Additional malformations in examined patients

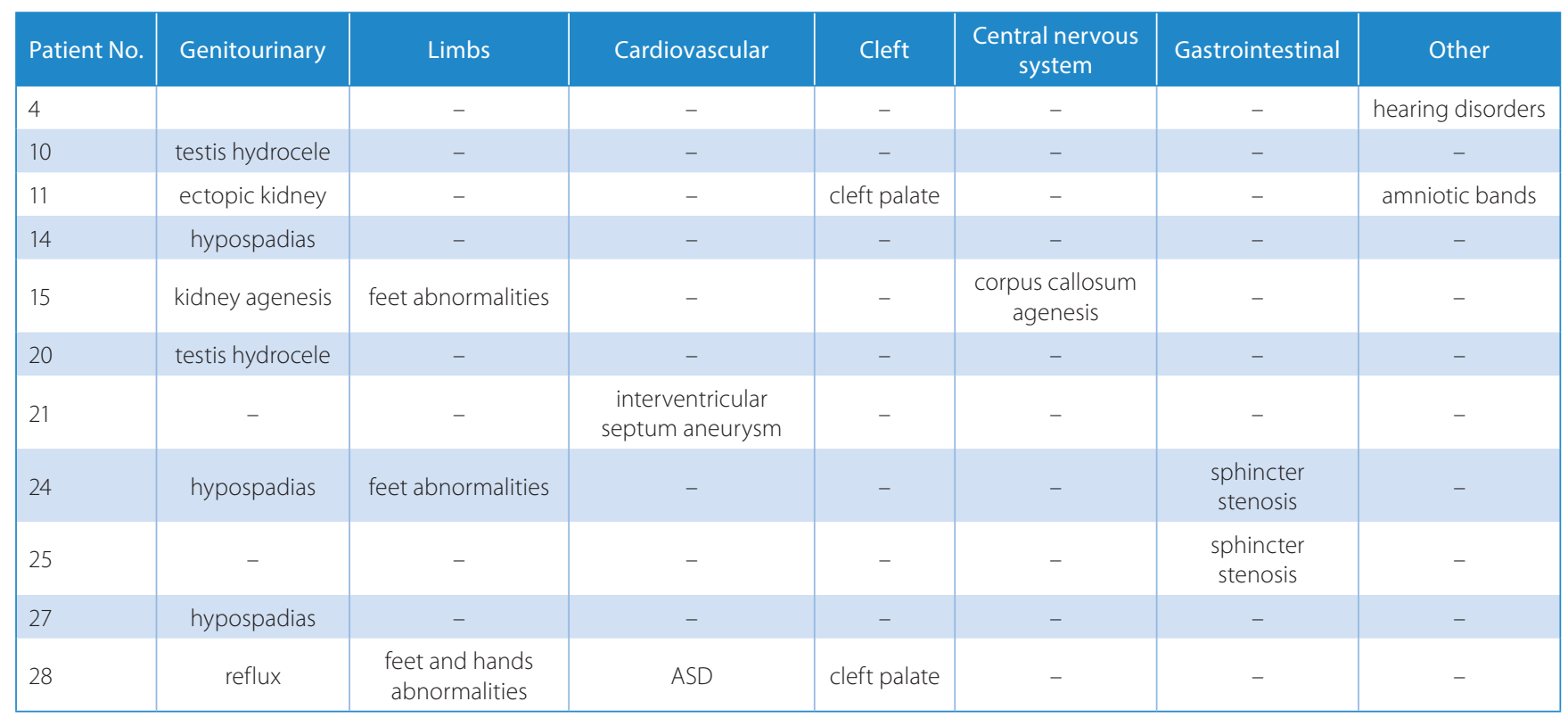

ASD - atrial septal defect.

Table 4. Division of patients according to Lajeunie et al. criteria

\begin{tabular}{|c|c|c|c|}
$\begin{array}{c}\text { Additional } \\
\text { malformations }\end{array}$ & $\begin{array}{c}\text { Group I } \\
(\mathrm{n}=19)\end{array}$ & $\begin{array}{c}\text { Group IIA } \\
(\mathrm{n}=8)\end{array}$ & $\begin{array}{c}\text { Group IIB } \\
(\mathrm{n}=3)\end{array}$ \\
\hline 1 malformation & 0 & 7 & 0 \\
$>1$ malformation & 0 & 1 & 3 \\
\hline
\end{tabular}

development disorders, muscle tone changes) and ophthalmological abnormalities were found in 7 patients. In no patient, optic nerve disc edema standing for intracranial hypertension was observed.

According to the Whitaker classification, out of 23 patients who underwent cranioplasty, 18 (78\%) were qualified to category I, which means that the treatment result was satisfactory and the patient did not require further treatment. In 4 patients, minor cranial deformities were observed which needed corrective procedures and these cases were included to category II. One patient was qualified to category III due to severe bitemporal hollowing. None of our patients were included into category IV, which would require major craniofacial procedure, duplicating or exceeding the original operation (Table 5) (Fig. 8-11).

In the group of patients who had undergone cranioplasty, a follow-up visit revealed 1 or more neurological abnormalities in 12 cases, i.e., intellectual disabilities

Table 5. Whitaker classification of patients after cranioplasty

\begin{tabular}{|l|c|}
\hline Whitaker classification category & Number of patients \\
\hline I & 18 \\
\hline II & 4 \\
\hline III & 1 \\
\hline IV & 0 \\
\hline
\end{tabular}

of various degrees (6 patients), frequent headaches (5 patients), ADHD (2 patients), autism symptoms (1 patient), and cerebral palsy (2 patients). An ophtalmological examination showed vision defects in 15 cases and, most frequently, they included strabismus (10 cases), astigmatism and myopia. In 1 patient, lacrimal fistula of the lower ducts was diagnosed. Average cephalic index was 78 (range: 72-86) and it was adequate to the values of mesocephalicintermediate skull.

\section{Discussion}

Over the last decades, the incidence of trigonocephaly has been increasing, currently making it the $2^{\text {nd }}$ most common type of isolated synostosis. In the Plastic Surgery Department in Polanica-Zdrój, the $1^{\text {st }}$ surgery for trigonocephaly was performed in 1988. Until 2000, 11 procedures of skull remodeling in children were carried out in order to correct this malformation. In the years 2000-2014, the number of patients operated on for trigonocephaly increased to 37 , which constituted $24 \%$ of all the cases treated for craniostenosis (without division into isolated and syndromic cases). Di Rocco et al. in their observations carried out on a large group of patients, including over 2,800 patients treated in 1 center in the period of 20 years, report a considerable increase in the number of patients operated on for craniosynostoses. ${ }^{9}$ During this 20 -year period the number of nonsyndromic patients increased progressively, from 90 cases in 1988 to 163 in 2007. Such increase might be caused by better diagnostics and recognition of skull malformations made by pediatricians as well as by a larger number of patients admitted to the specialist unit. However, this may be also the symptom of an increased prevalence 

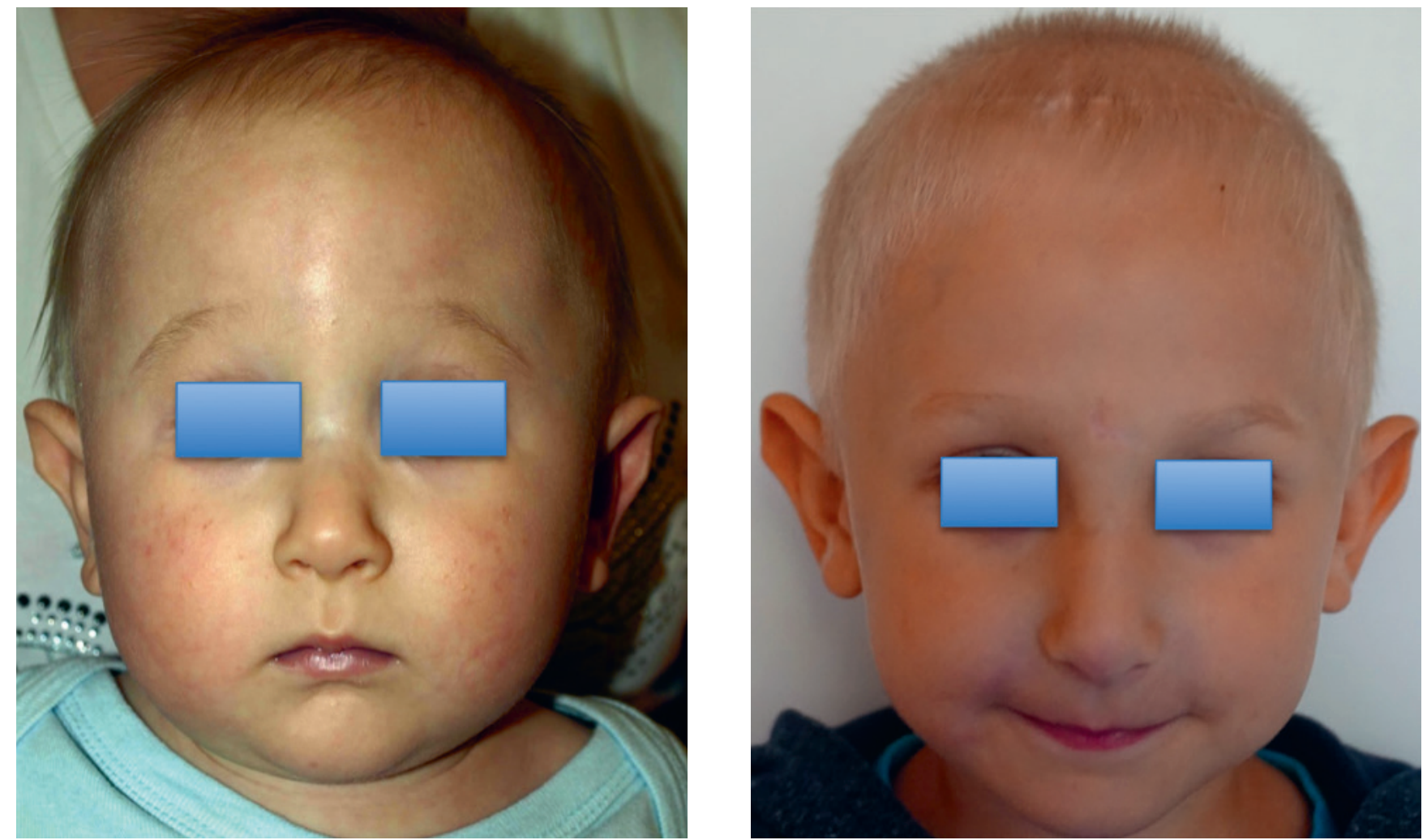

Fig. 8. Patient before the procedure (at the age of 21 months) and after the procedure at the age of 5 years
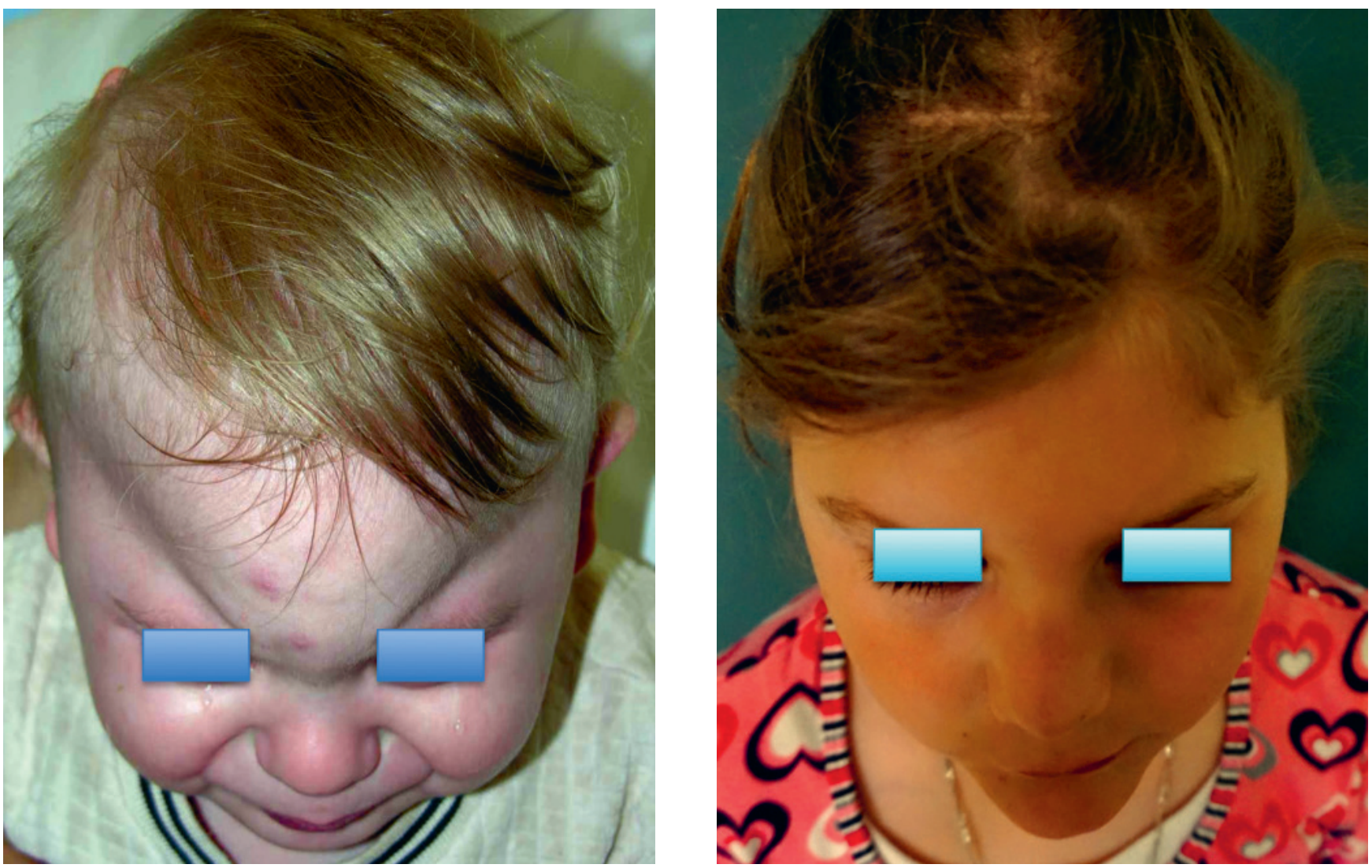

Fig. 9. Patient before the procedure (at the age of 8 months) and after the procedure at the age of 5 years 

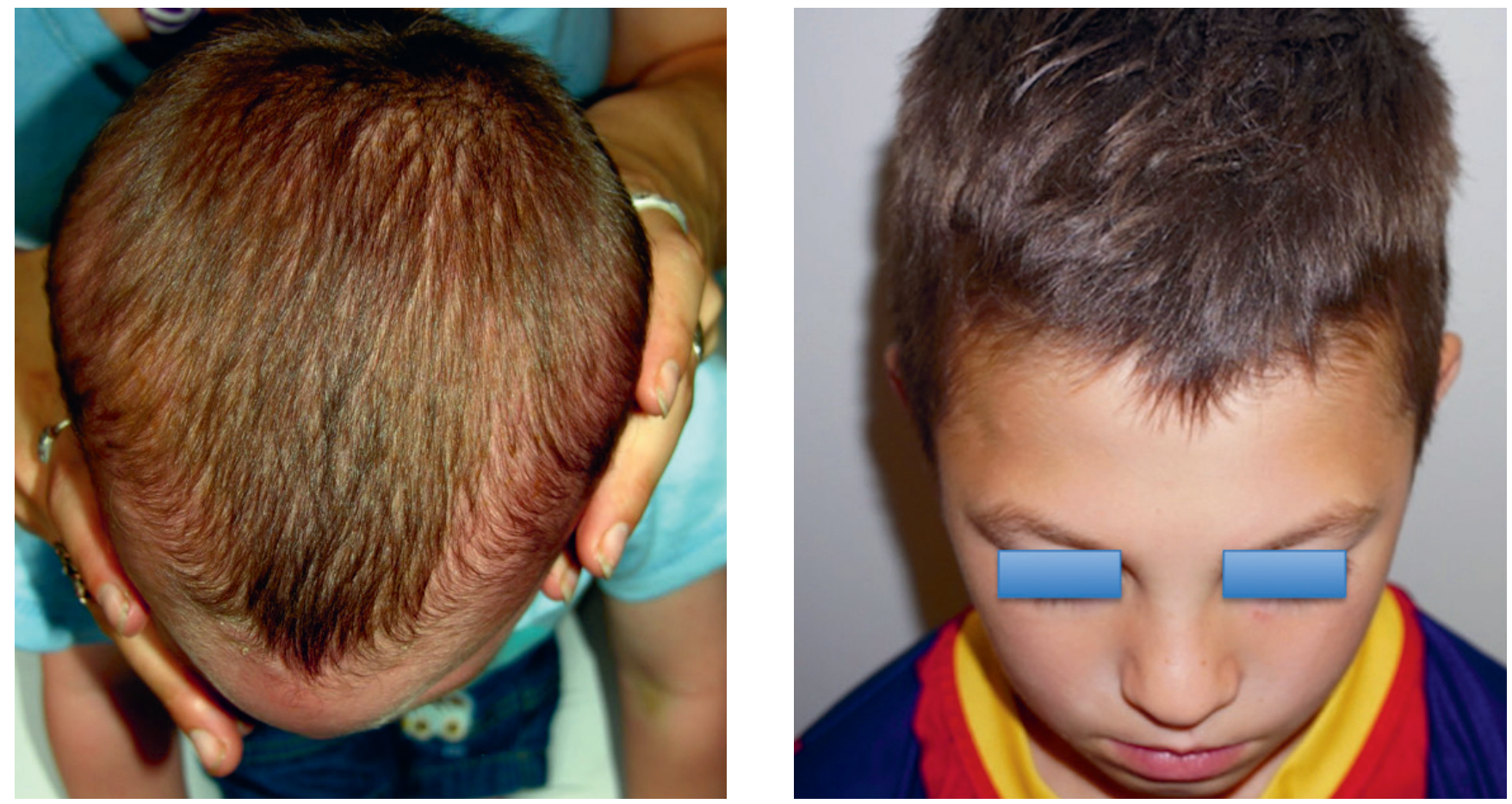

Fig. 10. Patient before the procedure (at the age of 8 months) and after the procedure (at the age of 4 years)
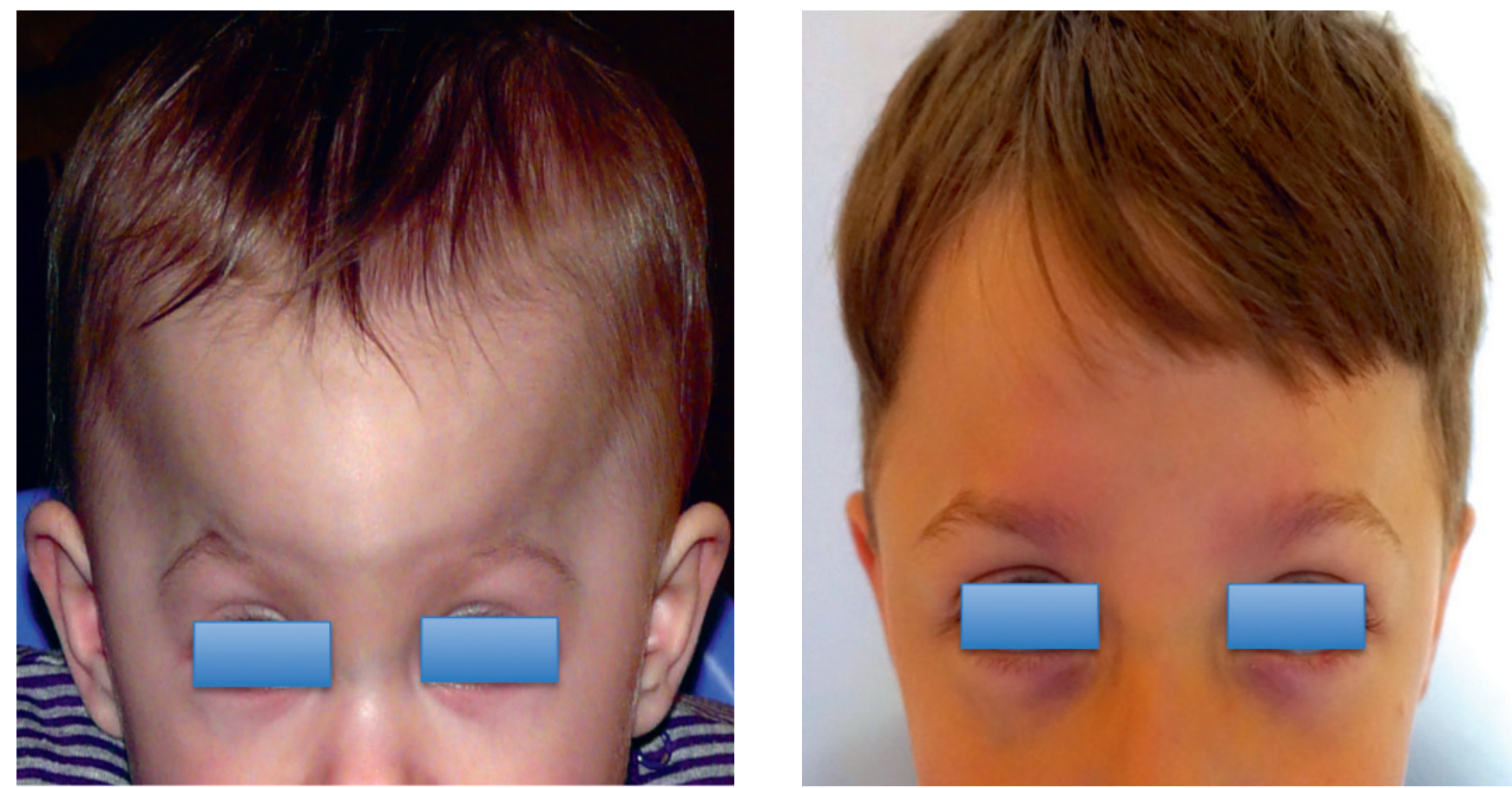

Fig. 11. Patient before the procedure (at the age of 7 months) and after the procedure (at the age of 7 years)

of cranial malformations. Trigonocephaly cases increased from 10 up to 42 cases a year and the number of scaphocephalies (the most common isolated form) from 48 up to 87 cases a year. What is interesting, the percentage of sagittal suture synostosis remained the same (53\%), whereas the percentage of trigonocephaly cases increased from $11 \%$ to $25 \%$ of all nonsyndromic cases. This phenomenon was also observed by van der Meulen et al. ${ }^{8}$ in their studies. The prevalence of metopic suture synostosis was estimated at 1:1,5000 live births, which made it the $3^{\text {rd }}$ most frequent single-suture craniosynostosis, after scaphocephaly $(1 / 4,200-1 / 8,500)$ and plagiocephaly $(1 / 1,1000)$. The percentage of trigonocephaly in publications discussing big groups of patients (>100 craniosynostosis patients) amounted to $3-10 \%$ of all operated cases in 1960s and 1970s. The pan-European study concerning 
the years 1997-2006, in which 3,240 patients were operated on in 7 participating units, showed a significant increase in the absolute number as well as of the percentage of trigonocephaly cases (23\%). Lajeunie et al. in their analysis of 237 trigonocephaly patients, observed a considerable predominance of male cases (M:F $=3,3: 1){ }^{4}$ In our group of patients, this ratio was identical.

Trigonocephaly is often accompanied by a malformation involving other systems. Taking into account the division proposed by Lajeunie et al., ${ }^{19}$ our patients may be divided into the following groups: group I $(\mathrm{n}=19)-$ patients with isolated malformation, and group II $(\mathrm{n}=11$; containing 2 subgroups: IIA - patients with additional malformations without any diagnosed syndrome $(\mathrm{n}=8)$, and IIB - patients with a recognized syndrome $(\mathrm{n}=3))$. Only in 1 patient from group IIA, more than 1 additional malformation was found, whereas this kind of abnormality was found in all patients from group IIB (Table 4). Among these cases, genitourinary system abnormalities $(\mathrm{n}=6)$ and limbs malformations $(\mathrm{n}=3)$ were predominant.

The reasons for trigonocephaly formation have not been clearly recognized yet; however, in accordance with 3 theories concerning disease etiology, genetic, metabolic or pharmacological factors may be considered, as well as fetal head intrauterine constraint or brain internal malformations. ${ }^{3}$ Patients in whom these factors might have appeared during fetal development, are listed in Table 2.

In our Department, before the surgery, a fundoscopy is performed to exclude increase of ICP and this symptom was not observed in any patient. Intracranial pressure increase is the most important factor which negatively influences brain development in the case of craniosynostosis. Disproportionate cranial cavity resulting from premature cranial suture synostosis may cause an increase in ICP, which is more common in the case of craniosynostoses involving many sutures as well as in syndromic cases $(30-40 \%)$. What is more, its prevalence is correlated with the patient's age at the time of surgery: the older the child, the bigger the probability of ICP increase.$^{20}$ In the majority of isolated craniosynostoses, ICP is doubled after 1 year of life and in the case of scaphocephalies, it is quadrupled. Optic nerve disc edema is a symptom of this process and it may result in nerve compression and loss of vision. Study results imply that edema develops at values $>15 \mathrm{~mm}$ $\mathrm{Hg}{ }^{21}$ Tuite et al. tested fundoscopy efficacy in ICP diagnosis and reported that optic nerve edema was correlated with increased ICP in $87 \%$ of patients in whom ICP was greater than $15 \mathrm{~mm} \mathrm{Hg.}{ }^{22}$ At the same time, in a group of patients younger than 8 years, edema directly suggests ICP increase, but the absence of this sign does not indicate lack of ICP increase. Hence, it cannot be excluded in patients treated in our Department. In patients with isolated craniosynostosis, ICP increase takes place in about $15-20 \%$ of cases, and in trigonocephaly it is even rarer $-8-17 \%$ of cases. ${ }^{23}$

In trigonocephaly, vision defects, such as primary strabismus or astigmatism, may occur. They are caused by deformities in the orbital, frontal and zygomatic areas, as well as abnormal attachments of oculomotor muscles, which forces affecting the eyeball are changed. ${ }^{24}$ The vision defects mentioned above were observed in our material as well.

In the group of children with trigonocephaly operated on after the $1^{\text {st }}$ year of life, Bottero et al. ${ }^{25}$ distinguished $52 \%$ of cases with psychomotor disorders. In the group of children operated on before the $1^{\text {st }}$ year of life, this percentage was significantly lower and comprised $22.6 \%$ of such cases. A higher risk of developmental disorders occurred in patients with additional extracranial abnormalities as well as in patients in whom the value of frontal stenosis was higher.

Nowadays, it is generally accepted that the surgery should be carried out before the $1^{\text {st }}$ year of life. ${ }^{26}$ In our center, patients are qualified for the procedure of skull remodeling for aesthetic or medical reasons at the age of 8-12 months. Mild malformations, which require milling or suture excision only, can be operated on at an older age. In some patients, however, surgical intervention is significantly delayed. This may be due to a late diagnosis made by a pediatrician or a neonatologist and delayed registration for the surgery in a specialist center. Sometimes, parents postpone their decision to operate their child because of the risky and extensive procedure.

The aim of surgical intervention is to excise prematurely fused suture and correct the associated deformities of the calvaria with remodeling and advancement of the forehead and supraorbital band. This enables the enlargement of the anterior cranial fossa and appropriate brain development as well as hypotelorism correction. ${ }^{27}$ Tessier and Marchac have largely contributed towards the development of trigonocephaly surgical treatment. At present, their methods are considered basic and many modifications have been implemented. Surgeries performed in our center are also based on these methods and their results are satisfactory.

In 5 cases, our patients required additional corrections mainly due to temporal hollowings, which are common complications in trigonocephaly treatment. Theories on its etiology focus either on bone or soft tissues damages during surgical procedures. Atrophy of the superficial temporal fat pad or temporal muscle could be another explanation for the appearance of these depressions. Van der Meulen et al. ${ }^{28}$ supported the theory that it is not the surgical technique but rather intrinsic synostotic bones defect that reduces the potential of osseous growth and is responsible for such a deformity. In turn, Oh et al. ${ }^{29}$ suggested that the incorrect surgical technique resulting in making the frontal bone too short creates a lack of bone in the temporal region. These conclusions are supported by a series of cases in which bitemporal depression disappeared after the application of bone grafts in the temporal areas.

Wes et $\mathrm{al}^{30}$ in their retrospective studies of trigonocephaly treatment carried out on a large group of patients 
( $\mathrm{n}=147$ ), found that with protracted time to follow-up visits, secondary deformations percentage increased. These deformations included bitemporal depressions and orbits lateral walls retrusion. They also observed a larger number of patients qualified to categories III and IV according to the Whitaker classification (independent factor in patients followed up after 5 years). In this study, almost $50 \%$ of patients were followed up after 5 years and as much as $36 \%$ of them were included to category III. In another study carried out on 60 patients, similar results were elicited and $85 \%$ of patients were qualified to category I in Whitaker classification. ${ }^{31}$ In our own study, though 17 patients registered for follow-up visits at the age over 5 years, the results were assessed as excellent and good (category I - 78\%).

Mortality and complication rates in trigonocephaly surgeries are low and dura mater tears, subgaleal hematomas, postoperative infections, and cerebrospinal fluid leakage are the most prevalent ones..$^{32}$ In our own study, only in 1 patient the complication appeared in the form of seroma, which was evacuated 10 days after the surgery.

In order to decrease blood loss during surgery, endoscopic procedures proposed by Jimenez et al. were applied..$^{33}$ This method was implemented in the 1990s and it was based on a simple suturectomy with the use of an endoscope. In the majority of patients operated on with the use of this method, surgery time was reduced to $52 \mathrm{~min}$ and blood loss to $26 \mathrm{~mL}$. These operations were performed before the $4^{\text {th }}$ month of life and postoperative treatment required helmet molding therapy for about 7 months. This method is restricted to young infants, preferably before the $4^{\text {th }}$ month of life. In older patients with severe and persistent malformations of the skull, results do not prove satisfactory.

The choice of surgery method depends on the severity of the malformation and the patient's age. Metzler et al. ${ }^{34}$ compared the FOA method with the tilt procedure, which is characteristic for leaving medial and lateral bone attachments of fronto-orbital segment in the area of frontonasal and frontozygomatic sutures and vascularized from trochlear, supraorbital and superficial frontal vessels. The tilt procedure carries benefits when applied in younger infants, as this group has malleable osseous segments, allowing greenstick fracture. The degree of surgical correction achievable using the tilt would be well-applied in cases of mild and moderate metopic synostosis. In severe cases, the larger magnitude of movement possible with FOA may allow for distinct 3D correction and overcorrection.

Apart from quite obvious characteristics of a triangle skull shape in all of our patients, 9 of them revealed additional malformations in preoperative imaging study. Many radiologically detected abnormalities in the cerebral region are associated with craniosynostoses - mainly syndromic ones. They may be divided into 3 categories. The $1^{\text {st }}$ one is general brain malformation strictly connected with mechanical compression and skull deformation. The $2^{\text {nd }}$ one concerns Chiari I malformation and is also caused by compression and posterior cranial fossa reduction, especially in premature synostosis of lambdoid suture. The $3^{\text {rd }}$ one is related to the white matter abnormalities. They range from ventriculomegaly and hydrocephalus to callosal anomalies or agenesis, hypoplasia or absence of the septum pellucidum, paucity or dysplasia of temporal white matter, distortions of the cerebral cortex, as well as pyramidal or hippocampus hypoplasia. Usually, these abnormalities were considered secondary to cranial growth inhibition. Tokumaru et al. found abnormalities within the hippocampus, corpus callosum and septum pellucidum to be primary abnormalities of brain development. ${ }^{35}$ This theory may be confirmed by the occurrence of neurological and behavioral disorders, despite corrective surgery. Fibroblasts growth factor mutations, which are the most common reason for syndromic craniosynostoses, play an important role in both cranium and brain development. ${ }^{36}$

Trigonocephaly is associated with a relatively high level of neurodevelopmental problems. These children frequently reveal speech and language development delay, as well as cerebral function disorders connected with frontal lobes dysfunction (ADHD, autism). ${ }^{37,38}$ In our own study, autism was diagnosed in 1 and ADHD was found in 2 patients. The total number of patients with neurological disorders was 12 . Hence, the question is whether surgical treatment performed before the $1^{\text {st }}$ year of life can prevent developmental and neurological disorders, which can be the result of primary brain dysfunction and not cranial suture synostosis. Additionally, our observations prove that some of our patients who had been diagnosed with neurological disorders before the surgery did not reveal them anymore after the procedure, and some revealed them after surgery. This may confirm the presumption that central nervous system lesions are primary and they occur regardless of the patient's age at the time of the surgery.

\section{Conclusions}

Early pediatric diagnostics makes it possible for the corrective surgery of the skull to be performed in the $1^{\text {st }}$ year of life. Surgical treatment based on Tessier's and Marchac's modified methods provides good results in patients at the age of about 12 months. The procedure performed at this age prevents consequences from ICP increase. Primary neurological and behavioral disorders may occur despite corrective surgery.

\section{References}

1. Vu HL, Panchal J, Parker EE, Levine NS, Francel P. The timing of physiologic closure of the metopic suture: A review of 159 patients using reconstructed 3D CT scans of the craniofacial region. J Craniofac Surg. 2001;12(6):527-532.

2. Persing JA, Jane JA, Shaffrey M. Virchow and the pathogenesis of craniosynostosis: A translation of his original work. Plast Reconstr Surg. 1989;83(4):738-742. 
3. van der Meulen J. Metopic synostosis. Child Nerv Syst. 2012;28(9): 1359-1367.

4. Lajeunie E, Le Merrer M, Marchac D, Renier D. Syndromal and nonsyndromal primary trigonocephaly: Analysis of a series of 237 patients. Am J Med Genet. 1998;75(2):211-215.

5. Engel M, Thiele OC, Muhling J, et al. Trigonocephaly: Results after surgical correction of nonsyndromatic isolated metopic suture synostosis in 54 cases. J Craniomaxillofac Surg. 2012;40(4):347-353.

6. Lajeunie E, Crimmins DW, Arnaud E, Renier D. Genetic considerations in nonsyndromic midline craniosynostoses: A study of twins and their families. J Neurosurg. 2005;103(4 Suppl):353-356.

7. van der Vlugt JJB, van der Meulen J, Creemers HE, Verhulst FC, Hovius SER, Okkerse JME. Cognitive and behavioral functioning in 82 patients with trigonocephaly. Plast Reconstr Surg. 2012;130(4): 885-893.

8. van der Meulen J, van der Hulst $R$, van Adrichem $L$, et al. The increase of metopic synostosis: A pan-European observation. J Craniofac Surg. 2009;20(2):283-286.

9. Di Rocco F, Arnaud E, Renier D. Evolution in the frequency of nonsyndromic craniosynostosis. J Neurosurg Pediatr. 2009;4(1):21-25.

10. Kweldam CF, van der Vlugt JJ, van der Meulen JJ. The incidence of craniosynostosis in the Netherlands, 1997-2007. J Plast Reconstr Aesthet Surg. 2011;64(5):583-588.

11. Cohen SR, Persing JA. Intracranial pressure in single-suture craniosynostosis. Cleft Palate Craniofac J. 1998;35(3):194-196.

12. Selber J, Reid RR, Gershman B, et al. Evolution of operative techniques for the treatment of single-suture metopic synostosis. Ann Plast Surg. 2007;59(1):6-13.

13. Tessier P. Definitive plastic surgical treatment of severe facial deformities of craniofacial dysostosis: Crouzons and Aperts diseases. Plast Reconstr Surg. 1971;48(5):419-442.

14. Marchac D. Radical forehead remodeling for craniostenosis. Plast Reconstr Surg. 1978;61(6):823-835.

15. Patel A, Chang CC, Terner JS, Tuggle CT, Persing JA. Improved correction of supraorbital rim deformity in craniosynostosis by the "tilt" procedure. J Craniofac Surg. 2012;23(2):370-373.

16. Di Rocco C, Frassanito P, Tamburrini G. The shell technique: Bilateral fronto-orbital reshaping in trigonocephaly. Childs Nerv Syst. 2013;29(12):2189-2194.

17. Marchac D, Renier D, Broumand S. Timing of treatment for craniosynostosis and faciocraniosynostosis: A 20-year experience. Br J Plast Surg. 1994;47(4):211-222.

18. Whitaker LA, Bartlett SP, Schut L, Bruce D. Craniosynostosis: An analysis of the timing, treatment, and complications in 164 consecutive patients. Plast Reconstr Surg. 1987;80(2):195-206.

19. Lajeunie E, Le Merrer M, Arnaud E, Marchac D, Renier D. Primary trigonocephaly: Isolated, associated and syndromic forms. Genetic study of a series of 278 patients. Arch Pediatr. 1998;5(8):873-879.

20. Tamburrini G, Caldarelli M, Massimi L, Santini P, Di Rocco C. Intracranial pressure monitoring in children with single suture and complex craniosynostosis: A review. Childs Nerv Syst. 2005;21(10): 913-921.
21. Walsh TJ, Garden JW, Gallagher B. Obliteration of retinal venous pulsations during elevation of cerebrospinal-fluid pressure. Am J Ophthalmol. 1969;67(6):954-956.

22. Tuite GF, Chong WK, Evanson J, et al. The effectiveness of papilledema as an indicator of raised intracranial pressure in children with craniosynostosis. Neurosurgery. 1996;38(2):272-278.

23. Campbell JW, Albright AL, Losken HW, Biglan AW. Intracranial hypertension after cranial vault decompression for craniosynostosis. Pediatr Neurosurg. 1995;22(5):270-273.

24. Denis D, Genitori L, Bardot J, Saracco JB, Choux M, Maumenee IH. Ocular findings in trigonocephaly. Graefes Arch Clin Exp Ophthalmol. 1994;232(12):728-733.

25. Bottero L, Lajeunie E, Arnaud E, Marchac D, Renier D. Functional outcome after surgery for trigonocephaly. Plast Reconstr Surg. 1998;102(4):952-958; discussion 959-960.

26. Renier D, Lajeunie E, Arnaud E, Marchac D. Management of craniosynostoses. Childs Nerv Syst. 2000;16(10-11):645-658.

27. Ozlen F, Kafadar AM, Abuzayed B, et al. Surgical treatment of trigonocephaly: Technique and long-term results in 48 cases. J Neurosurg Pediatr. 2011;7(5):565-565.

28. van der Meulen J, Willemsen J, van der Vlugt J, et al; Dutch Craniofacial Unit. On the origin of bitemporal hollowing. J Craniofac Surg. 2009;20(3):752-756.

29. Oh AK, Greene AK, Mulliken JB, Rogers GF. Prevention of temporal depression that follows fronto-orbital advancement for craniosynostosis. J Craniofac Surg. 2006;17(5):980-985.

30. Wes AM, Paliga JT, Goldstein JA, Whitaker LA, Bartlett SP, Taylor JA. An evaluation of complications, revisions, and long-term aesthetic outcomes in nonsyndromic metopic craniosynostosis. Plast Reconstr Surg. 2014;133(6):1453-1464.

31. Hormozi AK, Shahverdiani R, Mohammadi HR, Zali A, Mofrad HRH. Surgical treatment of metopic synostosis. J Craniofac Surg. 2011;22(1):261-265.

32. Esparza J, Hinojosa J. Complications in the surgical treatment of craniosynostosis and craniofacial syndromes: Apropos of 306 transcranial procedures. Childs Nerv Syst. 2008;24(12):1421-1430.

33. Jimenez DF, Barone CM, Cartwright CC, Baker L. Early management of craniosynostosis using endoscopic-assisted strip craniectomies and cranial orthotic molding therapy. Pediatrics. 2002;110(1 Pt 1):97-104.

34. Metzler P, Ezaldein $\mathrm{HH}$, Persing JA, Steinbacher DM. Comparing two fronto-orbital advancement strategies to treat trigonocephaly in metopic synostosis. J Craniomaxillofac Surg. 2014;42(7):1437-1441.

35. Tokumaru AM, Barkovich AJ, Ciricillo SF, Michael SB. Skull base and calvarial deformities: Association with intracranial changes in craniofacial syndromes. Am J Neuroradiol. 1996;17(4):619-630.

36. Raybaud C, Di Rocco C. Brain malformation in syndromic craniosynostoses, a primary disorder of white matter: A review. Childs Nerv Syst. 2007;23(12):1379-1388.

37. Speltz ML, Kapp-Simon KA, Cunningham M, Marsh J, Dawson G. Single-suture craniosynostosis: A review of neurobehavioral research and theory. J Pediatr Psychol. 2004;29(8):651-668.

38. Kapp-Simon KA, Speltz ML, Cunningham ML, Patel PK, Tomita T. Neurodevelopment of children with single suture craniosynostosis: A review. Childs Nerv Syst. 2007;23(3):269-281. 